\title{
Preliminary results of a non-invasive method to measure tumor size and distribution in vivo
}

\author{
SHU-LING FU ${ }^{1 *}$, CHIEN-AN CHEN ${ }^{2 *}$, LING-CHIEN HUNG ${ }^{1}$, MOON-SING LEE ${ }^{3,4}$, WEN-YEN CHIOU ${ }^{3,4}$, \\ HON-YI LIN ${ }^{3,4}$, YU-CHIEH SU ${ }^{4,5}$, CHING-CHIH LEE ${ }^{4,6}$ and SHIH-KAI HUNG ${ }^{3,4}$ \\ ${ }^{1}$ Institute of Traditional Medicine, National Yang-Ming University, Taipei 11221; \\ ${ }^{2}$ Department of Radiation Oncology, Zhongxing Branch, Taipei City Hospital, Taipei 10341; \\ ${ }^{3}$ Department of Radiation Oncology, Buddhist Dalin Tzu Chi Hospital, Chiayi 62247; \\ ${ }^{4}$ School of Medicine, Tzu Chi University, Hualian 97061; Departments of ${ }^{5}$ Hematological Oncology \\ and ${ }^{6}$ Otolaryngology, Buddhist Dalin Tzu Chi Hospital, Chiayi 62247, Taiwan, R.O.C.
}

Received June 13, 2015; Accepted August 5, 2016

DOI: $10.3892 /$ etm.2016.3819

\begin{abstract}
Molecular imaging of reporter gene expression in cancer cells can provide rapid, sensitive and non-invasive monitoring of tumor behavior. The aim of the present study was to establish a non-invasive method to measure tumor size and distribution in vivo. Briefly, H-Ras-transformed cells were stably transfected with a plasmid containing the luciferase gene (Luc), designated as Ras/Luc. Ras/Luc cells were injected into the back or tail vein of nude BALB/cAnN-Foxn1nu/CrlNarl mice (age, 6-8 weeks). Mice were subsequently administered D-luciferin via intra-peritoneal injection, prior to image acquisition. Photons emitted from the mice were detected via an imaging system. Tumor size and distribution in vivo were quantified as photons/second. Andrographolide has demonstrated radiosensitization in previous in vitro and in vivo studies. In the present study, the potential effects of andrographolide cancer metastasis were investigated further, using an imaging system. Preliminary results of andrographolide combined with radiation indicated the inhibition of cancer metastasis. The present mechanistic study of andrographolide-mediated effects demonstrated that activated extracellular signal regulated kinase protein and $\mathrm{H}_{2} \mathrm{O}_{2}$ production levels were significantly increased by andrographolide. In summary, the present study established a non-invasive method to measure tumor size and distribution in vivo and indicated
\end{abstract}

Correspondence to: Dr Shih-Kai Hung, Department of Radiation Oncology, Buddhist Dalin Tzu Chi General Hospital, 2 Ming Sheng Road, Chiayi 62247, Taiwan, R.O.C.

E-mail: oncology158@yahoo.com.tw

*Contributed equally

Key words: andrographolide, in vivo imaging system, Ras, metastasis that andrographolide may be a potential therapeutic strategy in cancer therapy.

\section{Introduction}

Cancer is a major cause of mortality worldwide. In clinical practice, metastasis is the primary challenge in cancer treatment as it is the most malignant facet of cancer progression and leads to large numbers of mortality. Metastasis is a complicated multi-step process, which includes loss of cellular adhesion, increased tumor motility and invasiveness, intravasation transport, survival in the circulatory system, extravasation and metastatic colonization in distant organs (1). Examining the impact of metastasis in vivo remains an important tool in preclinical studies for evaluating novel therapies and studying cancer metastasis (2). However, it is difficult to optimally evaluate metastasis in animal models. For example, only a limited number of studies have developed spontaneous lung metastases in transgenic mouse models $(3,4)$. A common limitations of these studies was that metastasis status was assessed in sacrificed mice; therefore, the tumor burden could not be accurately assessed in a living model $(2,5)$. However, molecular imaging of reporter gene expression in cancer cells may provide a rapid, sensitive and non-invasive method of monitoring tumor behavior. The aim of the present study was to establish a non-invasive method to measure tumor size and distribution in vivo.

Andrographolide, a bicyclic diterpenoid lactone, is the primary ingredient of the medicinal herb Andrographis paniculata. Andrographolide exhibits a broad spectrum of pharmacological activities including anti-oxidation, anti-inflammation, anti-viral and anti-cancer effects (6). Furthermore, andrographolide has demonstrated radiosensitization in vitro and in vivo (7), which was associated with the downregulation of protein kinase $\mathrm{B}(\mathrm{Akt})$ and nuclear factor kappa-light-chain-enhancer of activated $\mathrm{B}$ cells $(\mathrm{NF}-\kappa \mathrm{B})$ activity. Akt and NF- $\kappa \mathrm{B}$ activity have exhibited an association with tumor cell invasion and epithelial-mesenchymal transition $(8,9)$. These results imply that andrographolide may inhibit metastatic lesions. In the current study, the effect of 
andrographolide on cancer metastasis was investigated, using a novel imaging system.

\section{Materials and methods}

Reagents and antibodies. Andrographolide (98\% purity; Merck Millipore, Darmstadt, Germany) was dissolved in dimethyl sulfoxide (DMSO) as a concentrated stock solution. Primary monoclonal antibodies against anti-Ras (DCABH-9932) were purchased from Upstate Biotechnology Inc. (Lake Placid, NY, USA); phospho-p44/42 ErK1/2 (Thr202/Tyr204; 9101) and p44/42 p44/42 MAPK (Erk1/2; 4695) were purchased from Cell Signaling Technology, Inc., (Beverly, MA, USA). Horseradish peroxidase (HRP)-conjugated anti-rabbit IgG (A0545) and anti-mouse IgG (A9044) monoclonal secondary antibodies, and isoflurane and luciferin were purchased from Sigma-Aldrich (Merck Millipore, Darmstadt, Germany).

Cell culture. Rat kidney (RK3E/tv-a) cells were infected with a retrovirus carrying the oncogene H-Ras or control gene puromycin-N-acetyl-transferase (puro) as described in a previous study (10). Rat kidney (RK3E/tv-a) cells were kindly provided by Dr. Fu's laboratory (National Yang-Ming University, Taipei, Taiwan). Ras-expressing cells, but not puro-expressing cells, underwent malignant transformation in vitro and tumorigenesis in vivo. Cells were maintained as described previously (10). Subsequently, Ras-transformed cells were stably transfected with plasmids containing luciferase gene (Luc), and cells were designated as Ras/Luc. The oncogenicity, luciferase activity and Ras expression levels of this cell line were analyzed and validated.

Soft agar assays. Prior to use, 6-well plates were overlaid with $0.6 \%$ nutrient agar that contained Sea Plaque agar in Dulbecco's modified Eagle medium supplemented with $3 \%$ fetal bovine serum (FBS), 100 units/ml penicillin, $100 \mu \mathrm{g} / \mathrm{ml}$ streptomycin and $3 \mu \mathrm{g} / \mathrm{ml}$ puromycin. Ras/Luc cells $\left(10^{4}\right)$ were mixed well with $0.3 \%$ nutrient agar, seeded into prepared 6 -well plates and incubated at $37^{\circ} \mathrm{C}$ for two weeks. Every 3-4 days, the cells were replenished with $0.3 \%$ nutrient agar. Following two weeks of incubation, colonies were stained with crystal violet, photographed, and counted using a light microscope.

Luciferase assay. Ras/Luc cells $\left(10^{3}\right)$ were plated in a 96-well plate and cultured overnight at room temperature. For transfection, $0.1 \mathrm{mg}$ pGL3-reporter vectors and $10 \mathrm{ng}$ pRL-TK renilla internal control (Promega Corp., Madison, WI, USA) per well were co-transfected using Lipofectamine 2000 reagent (Invitrogen; Thermo Fisher Scientific, Inc., Waltham, MA, USA) according to the manufacturer's protocol. At $48 \mathrm{~h}$ post-transfection, cells were lysed in $100 \mathrm{ml} 6 \mathrm{X}$ passive lysis buffer at room temperature for $20 \mathrm{~min}$. For the luciferase assay, $30 \mathrm{ml}$ lysate was aliquoted into a 96-well plate to measure firefly luciferase and renilla luciferase activity. Fluorescence intensity was read with a luminometer by mixture cell lysate and luciferin (Beckman Coulter, Inc., Brea, CA, USA).

Western blot analysis. Cells $\left(10^{6}\right)$ were seeded into $100-\mathrm{mm}$ plates, incubated overnight, and collected by scraping and centrifugation at 1,200 $\mathrm{rpm}$ for $5 \mathrm{~min}$ at room temperature.
Cell pellets were subsequently lysed in radioimmune precipitation assay buffer (RIPA) supplemented with protease inhibitors. RIPA buffer was prepared with trisaminomethane (50 mM; pH 7.4), NaCl (150 mM), 1\% Nonidet P-40, $0.25 \%$ sodium deoxycholate, EDTA ( $5 \mathrm{mM}$; pH 8.0$)$ and EGTA (1 mM; pH 8.0). Cell suspensions were subsequently centrifuged at $13,000 \mathrm{rpm}$ for $20 \mathrm{~min}$ at $4^{\circ} \mathrm{C}$ to collect clear lysates, and the protein concentration was measured using the Bio-Rad protein assay kit (Bio-Rad Laboratories, Inc., Hercules, CA, USA). Total protein (50 $\mu \mathrm{g}$ lysate proteins) was separated by $10 \%$ SDS-PAGE and transferred to polyvinylidene difluoride membranes. Following blocking with 5\% non-fat milk/Tris-Buffered Saline-Tween-20 (TBST), membranes were incubated overnight with primary antibody including anti-Ras $(1: 1,000)$, anti-p-Erk $(1: 1,000)$ and anti-Erk $(1: 1,000)$ at $4{ }^{\circ} \mathrm{C}$ for $1 \mathrm{~h}$. Secondary HRP-conjugated anti-rabbit IgG (A0545) and anti-mouse IgG antibodies diluted in 1\% BSA/TBS/0.1\% Tween 20 (1:20,000) were sequentially incubated with the membranes for $1 \mathrm{~h}$ each at room temperature. Protein bands were visualized by chemiluminescence using an enhanced chemiluminescence detection system (Amersham Biosciences, Uppsala, Sweden). ImageJ software (version 1.40; National Institutes of Health, Bethesda, MA, USA) was used to quantify the intensity of the images.

In vivo tumorigenesis assays. The Ras/Luc cell line, which is a Ras-transformed cell line constitutively expressing the luciferase gene, was used in the present study. Briefly, $10^{6} \mathrm{Ras} / \mathrm{Luc}$ cells in $100 \mu \mathrm{l}$ phosphate-buffered saline were injected into the back or tail vein of nude mice. A total of 59 male (aged 6-8 weeks-old) nude mice (BALB/cAnN.Cg-Foxn1nu/CrlNarl) were obtained from the National Laboratory Animal Center (Tainan, Taiwan). BALB/cAnN-Foxn1nu/CrlNarl mice were maintained under 12-h light-dark cycle at room temperature $\left(24 \pm 1^{\circ} \mathrm{C}\right)$ and $60 \pm 5 \%$ humidity. They were provided with a standard diet and had ad libitum access to water during experimentation. In vivo bioluminescence images were captured every five days following tumor injection. Subsequently, mice were administered $150 \mathrm{mg} / \mathrm{kg}$ D-luciferin via intra-peritoneal injection $15 \mathrm{~min}$ prior to image acquisition. Mice were gas anesthetized with 1-3\% isoflurane, relocated to the warmed stage in the chamber and continuously exposed to $1-2 \%$ isoflurane for sustained sedation during imaging. The isoflurane level was adjusted according to the number of and weight of the animals in the chamber. Mice were in the chamber for 5-10 min and operators adjusted the gas flow to ensure mice were completely anesthetized. Photons emitted from mice were detected using the IVIS50 imaging system (Caliper Life Sciences, Inc., Alameda, USA) and regions of interest (ROIs) from displayed images were quantified as photons/second (ph/s) using the Living Image software (version 2; PerkinElmer Inc., Houston, TX, USA).

Following establishment of an imaging system to monitor tumor formation in vivo, mice were divided into four groups according to the various treatments administered: Group 1 $(\mathrm{n}=15)$, andrographolide $(10 \mu \mathrm{M})$; group $2(\mathrm{n}=15)$, radiation (2 Gy) and vehicle (100 $\mu$ l DMSO); group 3 ( $\mathrm{n}=14)$, andrographolide $(10 \mu \mathrm{M})$ plus radiation $(2 \mathrm{~Gy})$; and group $4(\mathrm{n}=15)$, vehicle (100 $\mu$ l DMSO). Andrographolide dosage was selected based on a previous in vivo study (7). Ras-transformed cells 

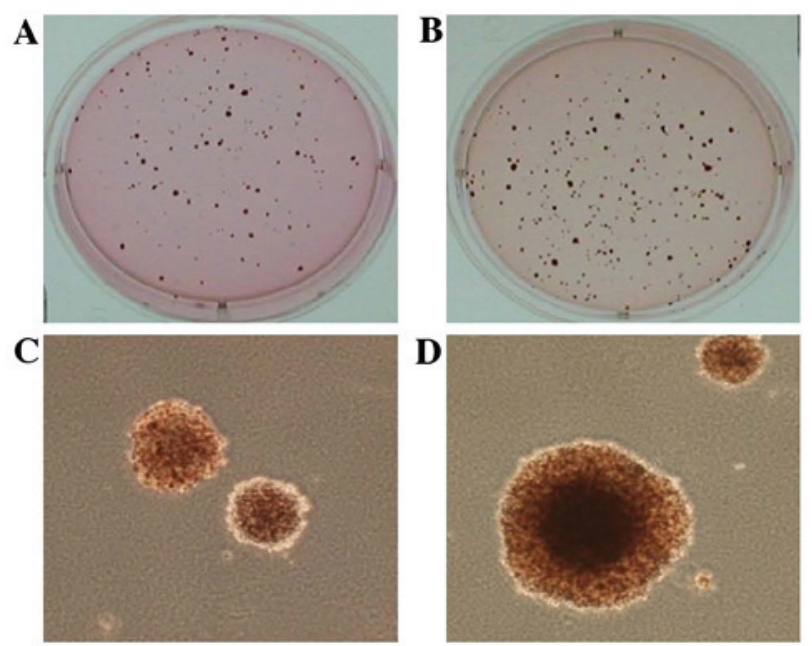

Figure 1. Growth of the Ras/luciferase cell line in soft agar. (A and B) Ras/Luc cells successfully grew in soft agar. (C) x100 magnification of A. (D) x100 magnification of $\mathrm{B}$.

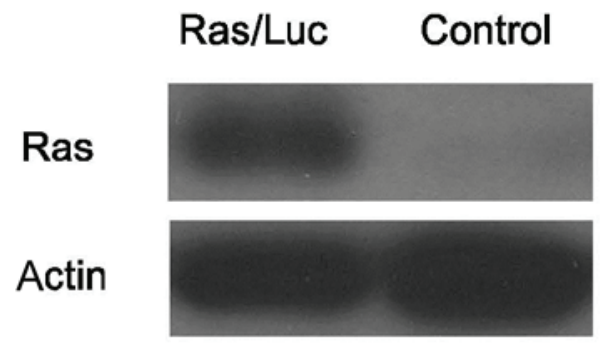

Figure 2. Ras expression in control cells and the Ras/Luc cell line, as detected by western blotting. Ras/Luc cells transfected with H-Ras oncogene and luciferase gene.

were injected into the tail vein and were traced periodically using the in vitro imaging system (IVIS). Andrographolide was administered concurrently with radiation. Cobalt-60 gamma rays (Atomic Energy of Canada Limited, Chalk River, Ontario, Canada) were used for radiation. Mice body weights were recorded every week. ROIs from displayed images were drawn around the tumor and the size of interested organs and their $\mathrm{ph} / \mathrm{s}$ were quantified. All animal protocols were performed according to the instructions issued by the Institutional Animal Care and Use Committee of National Yang-Ming University (Taipei, China). Following IVIS examination, the mice were sacrificed by cervical dislocation, and their tissues were subsequently examined.

Determination of $\mathrm{H}_{2} \mathrm{O}_{2}$ level. Cells $\left(2 \times 10^{5}\right)$ were seeded into 6-well plates and cultured overnight in a $\mathrm{CO}_{2}$ incubator at $37^{\circ} \mathrm{C}$. The medium was removed $24 \mathrm{~h}$ later and replaced with fresh medium with or without andrographolide. $\mathrm{H}_{2} \mathrm{O}_{2}$ levels were measured following exposure of Ras-transformed cells to $10 \mu \mathrm{M}$ andrographolide for $3 \mathrm{~h}$, with or without radiation treatment. Following another 3 -h interval, cells were collected. The effects of andrographolide under various conditions on the generation of intracellular $\mathrm{H}_{2} \mathrm{O}_{2}$ were determined via 2',7'-dichlorofluorescin diactetate $\left(\mathrm{DCFH}_{2}\right.$-DA) treatment. Flow cytometry (wavelength, 505/535 nm) was used to

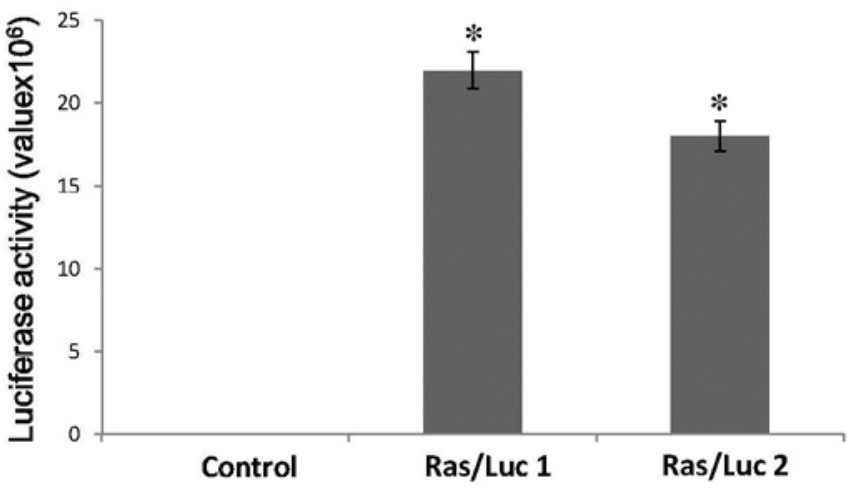

Figure 3. Luciferase activity in the Ras/luciferase cell line and control cells. Two different Ras-transformed cells stably transfected with plasmids containing Luc were established, designated as Ras/Luc 1 and 2. The Ras/Luc cell lines exhibited significant luciferase activity compared with the control cells $\left({ }^{*} \mathrm{P}<0.05\right)$.

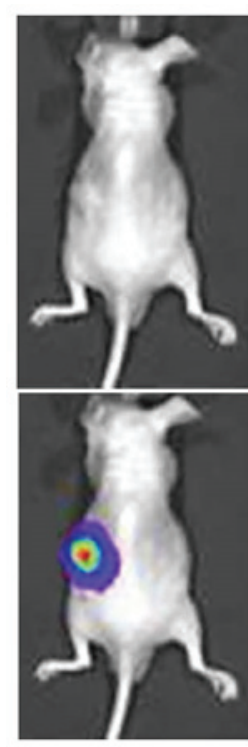

1 week

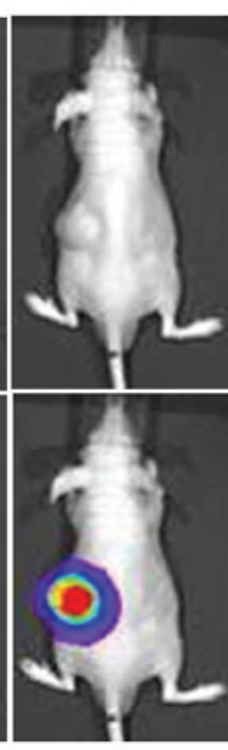

2 week

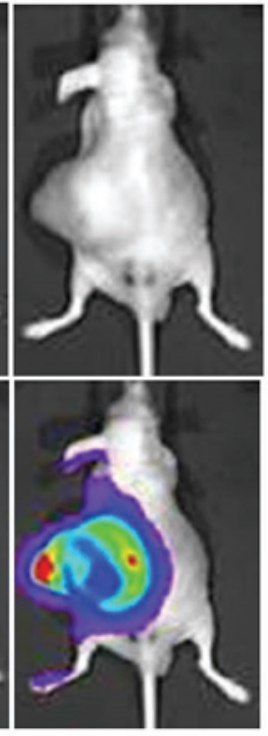

3 week
Figure 4. Bioluminescence imaging of tumors in nude mice at the indicated time intervals following transplantation of $\mathrm{H}$-Ras and luciferase expressing cells, detected via a novel in vivo imaging system following luciferin injection.

determine dichlorodihydrofluoroscein (DCF) fluorescence intensity (Becton Dickinson, Lincoln Park, NJ, USA). For control experiments, $5 \mu \mathrm{M} \mathrm{N}$-acetylcysteine and $0.03 \% \mathrm{H}_{2} \mathrm{O}_{2}$ were added to the culture $30 \mathrm{~min}$ prior to adding $\mathrm{DCFH}_{2}$-DA.

Statistical analysis. SPSS software (version 21; IBM SPSS, Armonk, NY, USA) was used for statistical analyses. Data are presented as mean \pm standard deviation of three independent, duplicated experiments. Statistical analyses were performed using two-tail unpaired Student's t-test to compare two groups of data. $\mathrm{P}<0.05$ was considered to indicate a statistically significant difference.

\section{Results}

Establishment of a non-invasive method to measure tumor size and distribution in vivo. Initially, Ras-transformed cells 


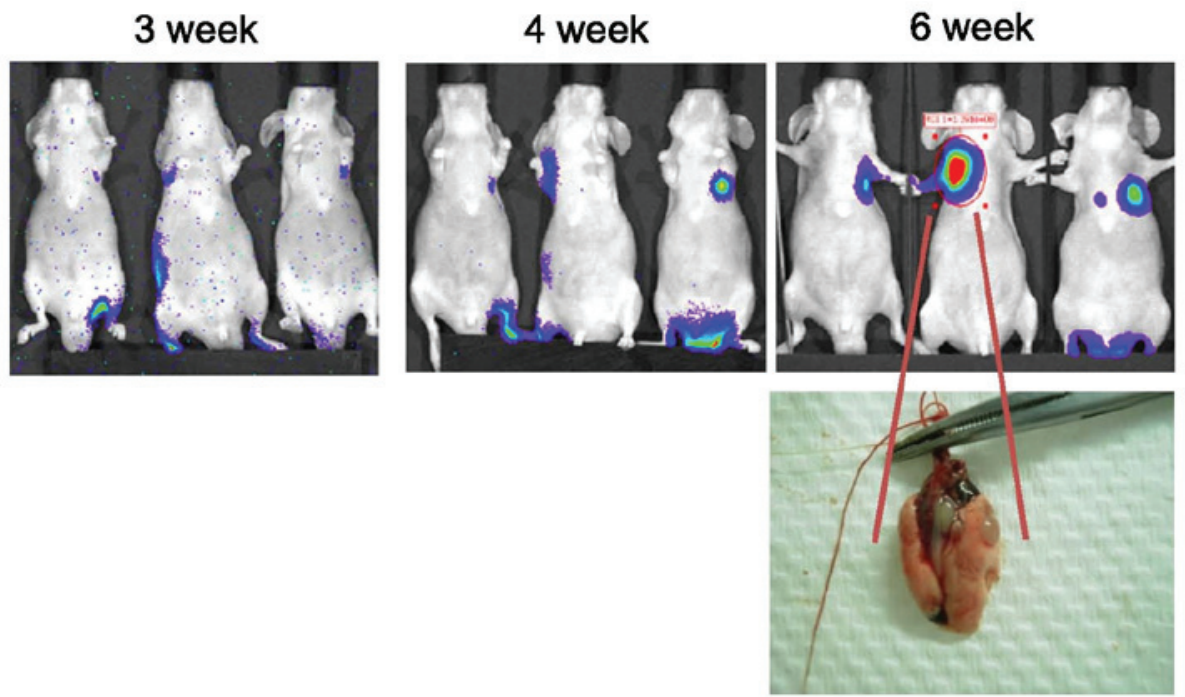

Figure 5. Bioluminescence imaging of in vivo metastatic activity in nude mice at the indicated time intervals following transplantation of H-Ras and luciferase expressing cells into the tail vein, as detected via a novel in vivo imaging system following luciferin injection.

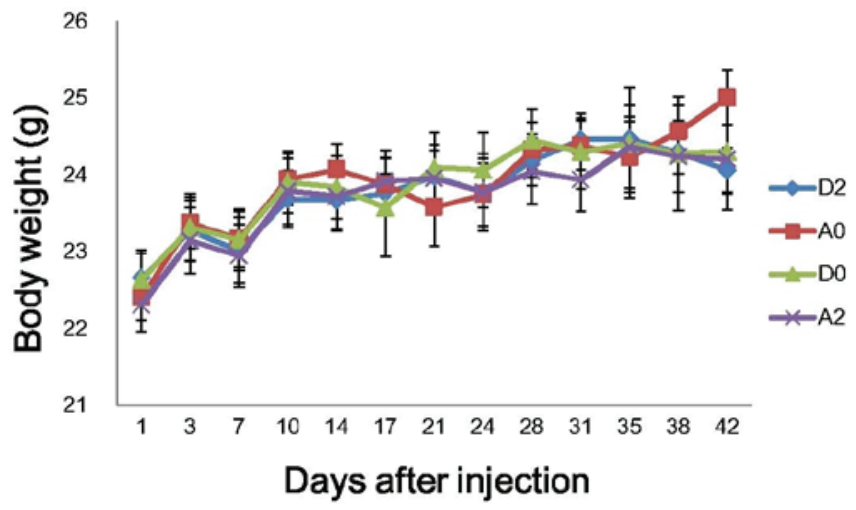

Figure 6. Andrographolide and/or radiation did not significantly influence body weight of nude mice. A2, andrographolide $(10 \mu \mathrm{M})$ plus radiation (2 Gy); A0, andrographolide (10 $\mu \mathrm{M})$; D2, radiation (2 Gy); D0, DMSO (100 $\mu 1 ;$ control).

stably transfected with plasmids containing Luc were established, designated as Ras/Luc, and the oncogenicity, luciferase activity and Ras expression of this cell line were determined. As shown in Fig. 1, Ras/Luc cells successfully grew in soft agar, which is one of the hallmark characteristics of cellular transformation and uncontrolled cell growth. As indicated in Figs. 2 and 3, the Ras/Luc cell line exhibited luciferase activity and Ras expression.

Tumorigenesis was tested in vivo. Ras/Luc cells were subcutaneously transplanted into the back of nude mice and subsequently, the presence of tumors was detected via bioluminescence imaging using IVIS following luciferin injection (Fig. 4). In addition, the metastatic activity of Ras/Luc cells in vivo was also examined using IVIS. Ras-transformed cells were injected into the tail vein and traced periodically using IVIS. As shown in Fig. 5, lung metastases were detected by IVIS, as photons emitted from the mice were detected and ROIs were quantified as $\mathrm{ph} / \mathrm{s}$. IVIS can detect and quantify absolute signals. These results are reproducible (11). Following the experimental stage of the present study, the tumor burden was

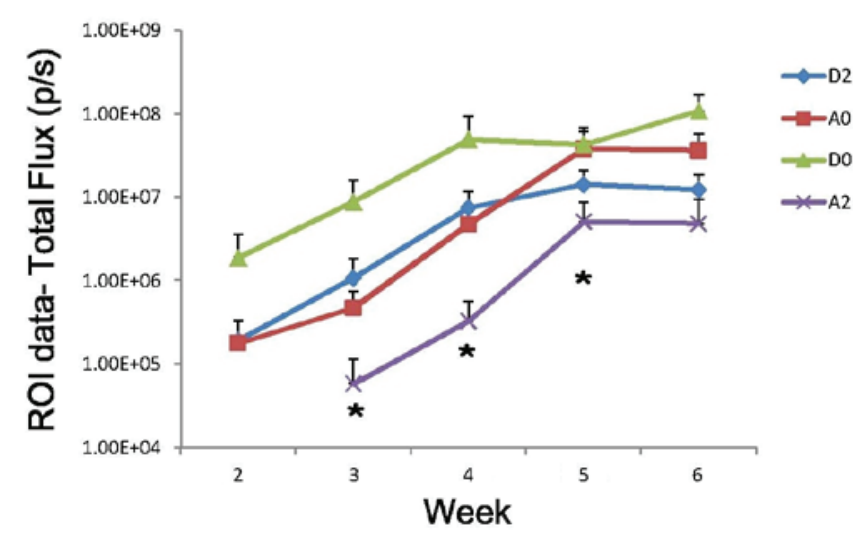

Figure 7. Andrographolide treatment with radiation significantly inhibits cancer metastasis. ${ }^{*} \mathrm{P}<0.05$ vs. D0, A0 and D2. ROI, region of interest; A2, andrographolide $(10 \mu \mathrm{M})$ plus radiation $(2 \mathrm{~Gy})$; $\mathrm{A} 0$, andrographolide $(10 \mu \mathrm{M})$; D2, radiation (2 Gy); D0, DMSO (100 $\mu$ l; control).

measured in the sacrificed mice. Lung tissue was dissected and the anatomical location was detected and confirmed (Fig. 5). However, the tumor size was difficult to accurately assess due to their small sizes and metastatic conditions. Despite this limitation, the results of the present study were unlikely to have been compromised. The successful establishment of IVIS with a Ras/Luc mouse xenograft model facilitated evaluation of tumor kinetics and the metastatic spread of tumors.

Effects of combined treatment with andrographolide and radiation on cancer metastasis. Various treatments were examined among the four groups. No significant alterations in body weight were detected following andrographolide and/or radiation treatment (Fig. 6). As shown in Fig. 7, andrographolide treatment with radiation significantly inhibited cancer metastasis $(\mathrm{P}<0.05)$. Mice lung metastatic rates are presented in Table I. The ratio among vehicle, andrographolide $(10 \mu \mathrm{M})$, radiation $(2 \mathrm{~Gy})$ and andrographolide $(10 \mu \mathrm{M})$ plus radiation (2 Gy) was 73.3, 53.3, 53.3 and 28.6 , respectively. 
Table I. Lung metastatic rate in mice.

Tumorigenesis in lung area

\begin{tabular}{lcc}
\hline Group & Mice with tumors/mice injected & Ratio (\%) \\
\hline D0 & $11 / 15$ & 73.3 \\
A0 & $8 / 15$ & 53.3 \\
D2 & $8 / 15$ & 53.3 \\
A2 & $4 / 14$ & 28.6 \\
\hline
\end{tabular}

A2, andrographolide $(10 \mu \mathrm{M})$ plus radiation (2 Gy); A0, andrographolide (10 $\mu \mathrm{M})$; D2, radiation (2 Gy); D0, DMSO (100 $\mu \mathrm{l}$; control).

The preliminary results indicated that andrographolide had an inhibitive effect on cancer metastasis.

Activated Erk protein expression levels are significantly increased by andrographolide. Whether the anti-cancer effect of andrographolide was associated with the Erk signaling pathway was investigated. Notably, western blot analysis showed significant andrographolide-induced phosphorylation of Erk (Thr202/Tyr204) with or without radiation $(\mathrm{P}<0.05)$, indicating that andrographolide treatment may lead to Erk activation (Fig. 8).

Andrographolide induces $\mathrm{H}_{2} \mathrm{O}_{2}$ production. Fig. 9 demonstrates that the intensity of DCF fluorescence increased following andrographolide treatment, indicating an overproduction of $\mathrm{H}_{2} \mathrm{O}_{2}$ in Ras-transformed cells, compared with the control cells. ${ }^{*} \mathrm{P}<0.05$.

\section{Discussion}

Cancer is characterized by uncontrolled tumor growth, invasion, and metastasis (12). Metastasis is a complicated multi-step process that provides a major challenge for cancer treatment. Furthermore, it is difficult to utilize a living animal model to optimally evaluate metastasis status in vivo. The aim of the present study, was to establish a non-invasive method to measure tumor size and distribution in vivo. Tumorigenesis and metastasis were successfully detected by IVIS; therefore, a non-invasive method to measure tumor size and distribution in vivo was established. Furthermore, the animal model established was used to examine the kinetics of tumor growth and metastasis in vivo.

Andrographolide has various pharmacological properties, including anti-oxidative, anti-inflammatory, antiviral and anti-cancer effects (13-15). The authors of the present study have previously demonstrated that andrographolide is able to sensitize Ras-transformed cells to radiation in vitro and in vivo (7). In the present study, the role of combined radiation and andrographolide treatment in reducing metastatic activity of Ras-transformed cells in vivo was investigated via this model. Andrographolide combined with radiation significantly inhibited cancer metastasis.

Multiple signaling pathways, including PI3K/Akt, and $\mathrm{NF}-\kappa \mathrm{B}$, are highly associated with metastatic activity. The

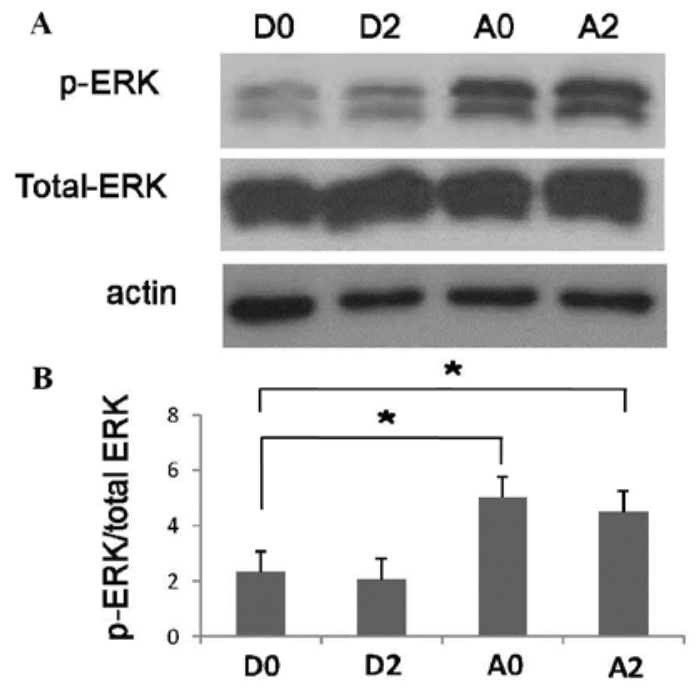

Figure 8. Activated Erk protein levels are significantly increased by andrographolide treatment. (A) p-Erk and Erk protein expression levels under various conditions. Actin was the loading control. (B) Quantitative analysis of western blotting. In each treatment, p-Erk protein levels were normalized to those of Erk. "P<0.05 vs. D0. Erk, extracellular signal regulated kinase; p, phosphorylated; A2, andrographolide $(10 \mu \mathrm{M})$ plus radiation $(2 \mathrm{~Gy}) ; \mathrm{A} 0$, andrographolide (10 $\mu \mathrm{M})$; D2, radiation (2 Gy); D0, DMSO (100 $\mu \mathrm{l}$; control).

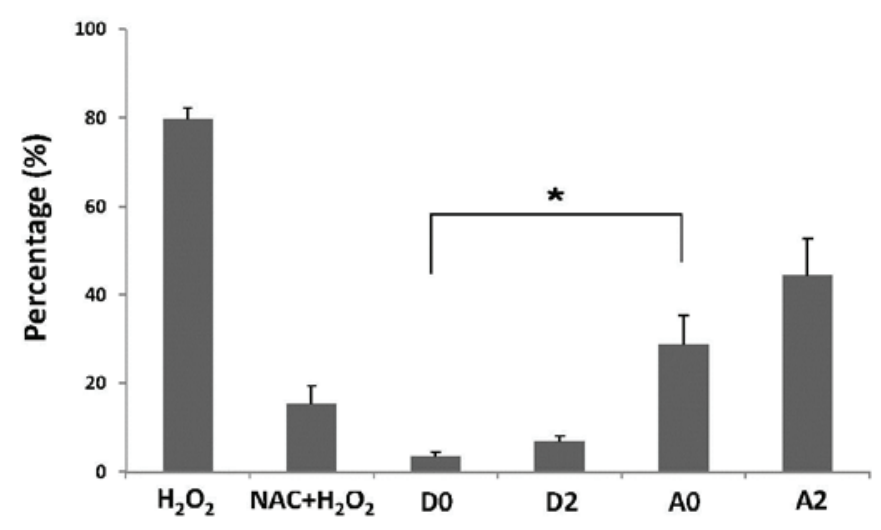

Figure 9. Andrographolide induces $\mathrm{H}_{2} \mathrm{O}_{2}$ production. Data showed that the intensity of DCF fluorescence increased following andrographolide treatment compared with that of the control. Cells treated with NAC exhibited a lower $\mathrm{H}_{2} \mathrm{O}_{2}$ level. Quantitative data based on three independent experiments are shown. Data were compared by two-tail Student's t-test. ${ }^{*} \mathrm{P}<0.05$ vs. D0. NAC, N-acetylcysteine; A2, andrographolide $(10 \mu \mathrm{M})$ plus radiation (2 Gy); $\mathrm{A} 0$, andrographolide $(10 \mu \mathrm{M})$; D2, radiation (2 Gy); D0, DMSO (100 $\mu$; control).

PI3K/Akt/mTOR pathway regulates VEGF expression in various tumors to control angiogenesis (16). Another study reported that activation of the PI3K/Akt/mTOR/p70S6K pathway promoted the viability and migration of colorectal cancer cells (17). Furthermore, overexpression of the NF-кB pathway was demonstrated to be sufficient to increase colorectal cancer cell proliferation, motility and metastasis (18). These results indicate that the PI3K/Akt and NF- KB signaling pathways have an important role in cancer cell metastatic activity (19). The authors of the present study have previously demonstrated that NF- $\kappa \mathrm{B}$ activity was elevated by radiation and significantly reduced by andrographolide combined with radiation, and that the level of activated 
Akt protein was also significantly reduced by andrographolide (7). These findings indicated that andrographolide may exhibit reductive effects on cancer metastasis. However, the cellular mechanisms responsible for this phenomenon are yet to be elucidated.

Active Erk regulates various cytoplasmic and nuclear targets that perform important cellular functions, including proliferation, migration, differentiation and death $(20,21)$. Nevertheless, previous studies have indicated that Erk-signaling pathways increase cell survival, primarily by promoting the activity of anti-apoptotic proteins and repressing pro-apoptotic proteins $(22,23)$. However, an increasing number of studies have demonstrated that Erk is associated with two apparently opposing processes; aberrant Erk activation has been demonstrated to promote cell death, and Erk activity has reportedly been implicated in cell death induced by various anticancer drugs (23-25). Notably, Erk activation requires ROS production to induce cell death (26). In the present study, andrographolide was able to induce Erk activation and $\mathrm{H}_{2} \mathrm{O}_{2}$ production. Therefore, the Erk pathway may be involved in andrographolide-mediated anti-cancer effects.

In vivo bioluminescence imaging utilizes the light emitted by luciferases to produce a functional image. The photons emitted are able to penetrate the whole body and can be applied to monitor deep tumors. This type of analysis enables studies of gene expression, tumor growth, and cell migration over time in live animals (27). For studies of the mechanisms of novel drugs or radiation, this system is valuable for pre-clinical in vivo evaluation and accelerates the experimental process to efficiently generate results. Notably, tumor cell death, necrosis and metastasis can be detected earlier due to sensitive signal changes (11). However, this method has several limitations. Firstly, activity is restricted to the intracellular environment (27). Secondly, this system may only be used for pre-clinical in vivo evaluations and cannot be used in humans as luciferin is required to activate a reporter gene; therefore, the procedure still raises ethical questions. Thirdly, this system forms a type of biological image; therefore the quantification signals require a baseline for comparison. Although it may be influenced by several orders of signal magnitude, it is not compromising the quantitative result (25).

In the present study, a Ras/Luc cell line was constructed. Activating Ras mutations are frequently found in human tumors and the H-Ras oncogene is correlated with radiation resistance (7). The novel imaging method used in the present study may provide a rapid, sensitive and non-invasive technique for assessing therapies, and studying cancer metastasis and radiotherapy.

In conclusion, the present study established a non-invasive method to measure tumor size and distribution in vivo. Furthermore, andrographolide combined with radiation demonstrated an ability to inhibit cancer metastasis, which merits further study to elucidate the mechanisms involved.

\section{Acknowledgements}

This study was supported by the Buddhist Dalin Tzu Chi General Hospital [grant no. DTCRD101(2)-I-13].

\section{References}

1. Meyer T and Hart IR: Mechanisms of tumour metastasis. Eur J Cancer 34: 214-221, 1998.

2. Zhang L, Gaskins K, Yu Z, Xiong Y, Merino MJ and Kebebew E: An in vivo mouse model of metastatic human thyroid cancer. Thyroid 24: 695-704, 2014.

3. Jin Y, Li F, Zheng C, Wang Y, Fang Z, Guo C, Wang X, Liu H, Deng L, Li C, et al: NEDD9 promotes lung cancer metastasis through epithelial-mesenchymal transition. Int J Cancer 134: 2294-2304, 2014

4. Zhu XG, Zhao L, Willingham MC and Cheng SY: Thyroid hormone receptors are tumor suppressors in a mouse model of metastatic follicular thyroid carcinoma. Oncogene 29: 1909-1919, 2010.

5. Kim WG, Guigon CJ, Fozzatti L, Park JW, Lu C, Willingham MC and Cheng SY: SKI-606, an Src inhibitor, reduces tumor growth, invasion, and distant metastasis in a mouse model of thyroid cancer. Clin Cancer Res 18: 1281-1290, 2012

6. Lim JC, Chan TK, Ng DS, Sagineedu SR, Stanslas J and Wong WS: Andrographolide and its analogues: Versatile bioactive molecules for combating inflammation and cancer. Clin Exp Pharmacol Physiol 39: 300-310, 2012.

7. Hung SK, Hung LC, Kuo CD, Lee KY, Lee MS, Lin HY, Chen YJ and Fu SL: Andrographolide sensitizes Ras-transformed cells to radiation in vitro and in vivo. Int J Radiat Oncol Biol Phys 77: 1232-1239, 2010

8. Qiao M, Sheng S and Pardee AB: Metastasis and AKT activation. Cell Cycle 7: 2991-2996, 2008.

9. Huber MA, Azoitei N, Baumann B, Grünert S, Sommer A, Pehamberger H, Kraut N, Beug $\mathrm{H}$ and Wirth T: NF-kappaB is essential for epithelial-mesenchymal transition and metastasis in a model of breast cancer progression. J Clin Invest 114: 569-581, 2004.

10. Fu SL, Huang YJ, Liang FP, Huang YF, Chuang CF, Wang SW and Yao JW: Malignant transformation of an epithelial cell by $\mathrm{v}$-Src via tv-a-mediated retroviral infection: A new cell model for studying carcinogenesis. Biochem Biophys Res Commun 338: 830-838, 2005.

11. Lim E, Modi KD and Kim J: In vivo bioluminescent imaging of mammary tumors using IVIS spectrum. J Vis Exp: pii: 1210, 2009.

12. Ruan K, Song G and Ouyang G: Role of hypoxia in the hallmarks of human cancer. J Cell Biochem 107: 1053-1062, 2009.

13. Ji LL, Wang Z, Dong F, Zhang WB and Wang ZT: Andrograpanin, a compound isolated from anti-inflammatory traditional Chinese medicine Andrographis paniculata, enhances chemokine SDF-1alpha-induced leukocytes chemotaxis. J Cell Biochem 95: 970-978, 2005

14. Wiart C, Kumar K, Yusof MY, Hamimah H, Fauzi ZM and Sulaiman M: Antiviral properties of ent-labdene diterpenes of Andrographis paniculata nees, inhibitors of herpes simplex virus type 1. Phytother Res 19: 1069-1070, 2005.

15. Liang FP, Lin CH, Kuo CD, Chao HP and Fu SL: Suppression of $\mathrm{v}$-Src transformation by andrographolide via degradation of the $\mathrm{v}$-Src protein and attenuation of the Erk signaling pathway. J Biol Chem 283: 5023-5033, 2008.

16. Xie SR, Wang Y, Liu CW, Luo K and Cai YQ: Liquiritigenin inhibits serum-induced HIF-1 $\alpha$ and VEGF expression via the AKT/mTOR-p70S6K signalling pathway in HeLa cells. Phytother Res 26: 1133-1141, 2012.

17. Wang H, Duan L, Zou Z, Li H, Yuan S, Chen X, Zhang Y, Li X, Sun H, Zha H, et al: Activation of the PI3K/Akt/mTOR/p70S6K pathway is involved in S100A4-induced viability and migration in colorectal cancer cells. Int J Med Sci 11: 841-849, 2014.

18. Gavert N, Ben-Shmuel A, Lemmon V, Brabletz T and Ben-Ze'ev A: Nuclear factor-kappaB signaling and ezrin are essential for L1-mediated metastasis of colon cancer cells. J Cell Sci 123: 2135-2143, 2010.

19. Vivanco I and Sawyers CL: The phosphatidylinositol 3-kinase AKT pathway in human cancer. Nat Rev Cancer 2: 489-501, 2002.

20. Ramos JW: The regulation of extracellular signal-regulated kinase (ERK) in mammalian cells. Int J Biochem Cell Biol 40: 2707-2719, 2008

21. Cagnol S and Chambard JC: ERK and cell death: Mechanisms of ERK-induced cell death-apoptosis, autophagy and senescence. FEBS J 277: 2-21, 2010

22. Balmanno K and Cook SJ: Tumour cell survival signalling by the ERK1/2 pathway. Cell Death Differ 16: 368-377, 2009. 
23. Martin P and Pognonec P: ERK and cell death: Cadmium toxicity, sustained ERK activation and cell death. FEBS J 277: 39-46, 2010.

24. Watabe M, Masuda Y, Nakajo S, Yoshida T, Kuroiwa Y and Nakaya K: The cooperative interaction of two different signaling pathways in response to bufalin induces apoptosis in human leukemia U937 cells. J Biol Chem 271: 14067-14072, 1996.

25. Kim YH,Lee DH, Jeong JH, Guo ZS and Lee YJ: Quercetin augments TRAIL-induced apoptotic death: Involvement of the ERK signal transduction pathway. Biochem Pharmacol 75: 1946-1958, 2008.
26. Sinha D, Bannergee S, Schwartz JH, Lieberthal W and Levine JS: Inhibition of ligand-independent ERK1/2 activity in kidney proximal tubular cells deprived of soluble survival factors up-regulates Akt and prevents apoptosis. J Biol Chem 279: 10962-10972, 2004.

27. von Degenfeld G, Wehrman TS and Blau HM: Imaging beta-galactosidase activity in vivo using sequential reporter-enzyme luminescence. Methods Mol Biol 574: 249-259, 2009 